\title{
Character attachment in team-based first person shooter game with respect to the role in the combat among Korean young gamers
}

\author{
Doo Heon Song ${ }^{1}$, Seunghun Lee ${ }^{2}$ \\ ${ }^{1,2}$ Department of Computer Games, Yong-In SongDam College, Republic of Korea \\ ${ }^{1,2}$ Department of Virtual Reality Contents, Young San University, Republic of Korea
}

\begin{tabular}{l}
\hline Article Info \\
\hline Article history: \\
Received Jul 31, 2020 \\
Revised Sep 22, 2020 \\
Accepted Oct 8, 2020 \\
\hline
\end{tabular}

Keywords:

Attacker

Character attachment

Defender

First person shooter

Supporter

Team based game

\section{Corresponding Author:}

Seunghun Lee

Department of Virtual Reality Contents

Young San University

Busan 48015, Korea Computer Games, Republic of Korea

Email: shlee@ysu.ac.kr

\begin{abstract}
Character attachment have been studied thoroughly from the view of psychology and media researches. In game playing, the player-avatar relationship is a form of character attachment and affects a good game design as well as management systems such as character customizing and in game purchasing policy. In this paper, we investigate such player-avatar relationship on the theme of team-based FPS where in general the attachment is not expected to be high. However, from the online survey for Tom Clancy's Rainbow 6 Siege mania groups, we find that there are different character attachment patterns with respect to the role of players in the teamattacker, defender, and supporter. It shows that attackers think avatar as an 'object, but the defenders show more 'avatar as others' than the attackers. The supporters show high responsibility for the avatar and their play style is most like 'avatar as symbiote' manner.
\end{abstract}

This is an open access article under the CC BY-SA license.

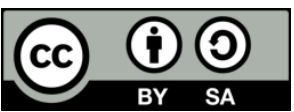

\section{INTRODUCTION}

Character identification is a psychological term used in literary and film studies to describe a psychological relationship between the spectator and a fictional character whereby the individual assimilates an aspect, property, or attribute of the other, i.e., the core meaning of identification is simple-to be like or to become like another. This concept of 'identification' is studied as early as Freud's work [1] and such relationship works positively in video game playing in extending the enjoyment [2]. This audiences' dispositions toward fictitious characters has been thoroughly studied in media entertainment research in that how audiences' moral salience might explain their reactions to character actions [3], narrative appeal [4], and how audiences react to media characters as if they were actual, physical people [5]. There have been many studies to verify the existence of such phenomenon in video game playing [6-8] and it influences game playing style as well [9].

In video games, however, gamers do not merely have a felt connection with their characters, but there exists an actual, tangible connection between the gamer and a fully functional, completely controllable avatar [4]. Thus, we use the concept of character attachment that is well summarized in [10] as individual's feeling of: i) a sense of friendship, ii) a sense of identification with a character, iii) if the individual can believe that the digital image is a real being, iv) if the individual feels a sense of responsibility to the 
character, and v) if the individual can reconcile the notion of control with both the friendship and identification aspects of the relationship. Character attachment has been found to be positively associated with game enjoyment and time spent playing games and motivations to play games for fantasy, diversion, and social interaction purposes [10].

This special emotional engagement between the player and game character can explain different behaviour of prosocial/antisocial players [11] and different style of control and effect in gaming [12]. Other researches of character attachment in video games include the relationship between character attachment and presence [13], and player-avatar interaction [14-17]. The player-avatar interaction studies induce four types of player-avatar relationship such as avatar-as-object, avatar-as-me, avatar-assymbiote, and avatar-as-other. When the player perceives the avatar as an object, the player-avatar relationship is nonsocial, and the player treats the avatar as merely a game piece or a tool which helps the player to achieve ingame goals; when the player perceives the avatar as him/herself, the player highly identifies with the avatar; when the player perceives as the avatar as a symbiote, the avatar is experienced as part of the player and the player is also part of the avatar; when the player perceives the avatar as another, the player and avatar relationship is social, and the player experiences the avatar as a distinct social entity [16].

One of the reasons that people should study player-avatar relationship is that the existence of such close tie affects game design and management in that close player-avatar relationship increases the desire of customizing characters [18] and thus increase in-game purchase [19]. Not only that, avatar death frequency is negatively correlated with player feelings of closeness (i.e., shared feelings) with their avatars and death penalty severity is positively correlated with player perceptions of their avatars as functional tools [20]. While previous studies in this domain usually explore the general aspect of game playing regardless of specific game genre, a study reveals that a certain genre of the video game playing might induce different player avatar emotional relationship by looking at romantic video games or dating simulation games in which players attempt to foster a romantic relationship with a chosen game character [21]. This result implies that there may exist some genre-specific aspects of player-avatar relationship.

In this paper, we investigate player-avatar relationship within a specific genre-team-based first person shooter (FPS). According to the recent report, FPS is the second most favorite genre in Korea only next to the massively multiplayer online role-playing games (MMORPG) regardless of age and gender [22, 23]. Also, team based FPS games have different roles inside the teams with specialized skills and weapons [24]. For the popular FPS game Overwatch, the dealer role plays the role of the main character in the team, but the rear support, or healer, is also important for the team's victory and tanker takes a voluntary sacrificing role to contribute for the team's winning. And those who seem to lack skills or want to be less responsible for winning or losing usually takes 'sub' role. However, disagreements often arise between gamers about team composition and the outcome of the match. Often, it develops to attack female gamers in the community [25].

Also, FPS genre games have some background story and plots to fulfill team's goal in the game, however, the effect of storytelling is not as deep as other genre in density [26]. Rather, team's winning is the highest goal of players but there are enough number of characters that the player can choose within the given roles in combat situation. Thus, in this paper, we will explore the following research question by empirical player survey within team-based FPS. Research Question: Will player-avatar relationship of team-based FPS exhibit different patterns with respect to the player's role in the game?

\section{METHOD}

\subsection{Game of investigation: Tom Clancy's Rainbow Six Siege}

We choose Tom Clancy's Rainbow Six Siege (Rainbow6 afterwards in this paper) as the game to be used in our online survey. Rainbow6 is a team-based FPS game developed and published by Ubisoft in 2015 [27]. The game has many play modes such as Hostage, Bomb, Secure area, Terrorist hunt etc. but in most cases of players vs. players $(\mathrm{PvP})$, it is a cooperative multiple player games of 5-players squad. Players take on the role of either attackers or defenders and must fight against each other. Unlike other FPS games, it is characterized by being able to use various crews with special abilities depending on the team and strategically using walls that can be partially pierced or reinforced in the map.

The avatars in this game, called operators, have a set of primary and secondary weapons that can be used for each unit. In general, weapons of the attacking side composed of those advantageous for long-range firefighting, such as assault rifles, light machine guns, and designated gunners whereas the defensive side has weapons that are advantageous for short-range firefighting, such as submachine guns and shotguns. There are 23 operators in each of the attacking and defending teams [28]. In order to help players to choose their favorite avatars, Rainbow6 provides an avatar positioning maps for each side to reveal that how high-tiered players choose each operators(pick rate) and how frequently that avatar wins in the game(win-rate) as shown in Figures 1 and 2 [29]. 

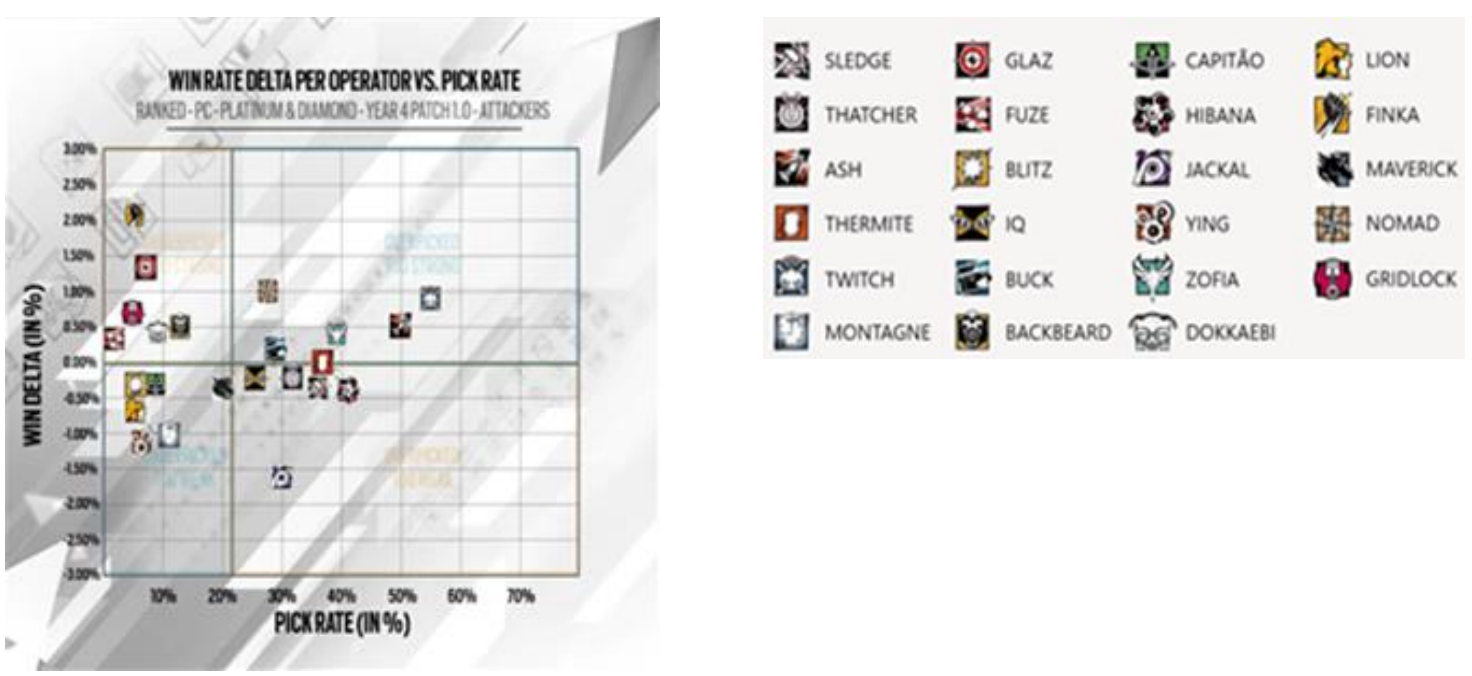

Figure 1. Stats for avatars of attacking side

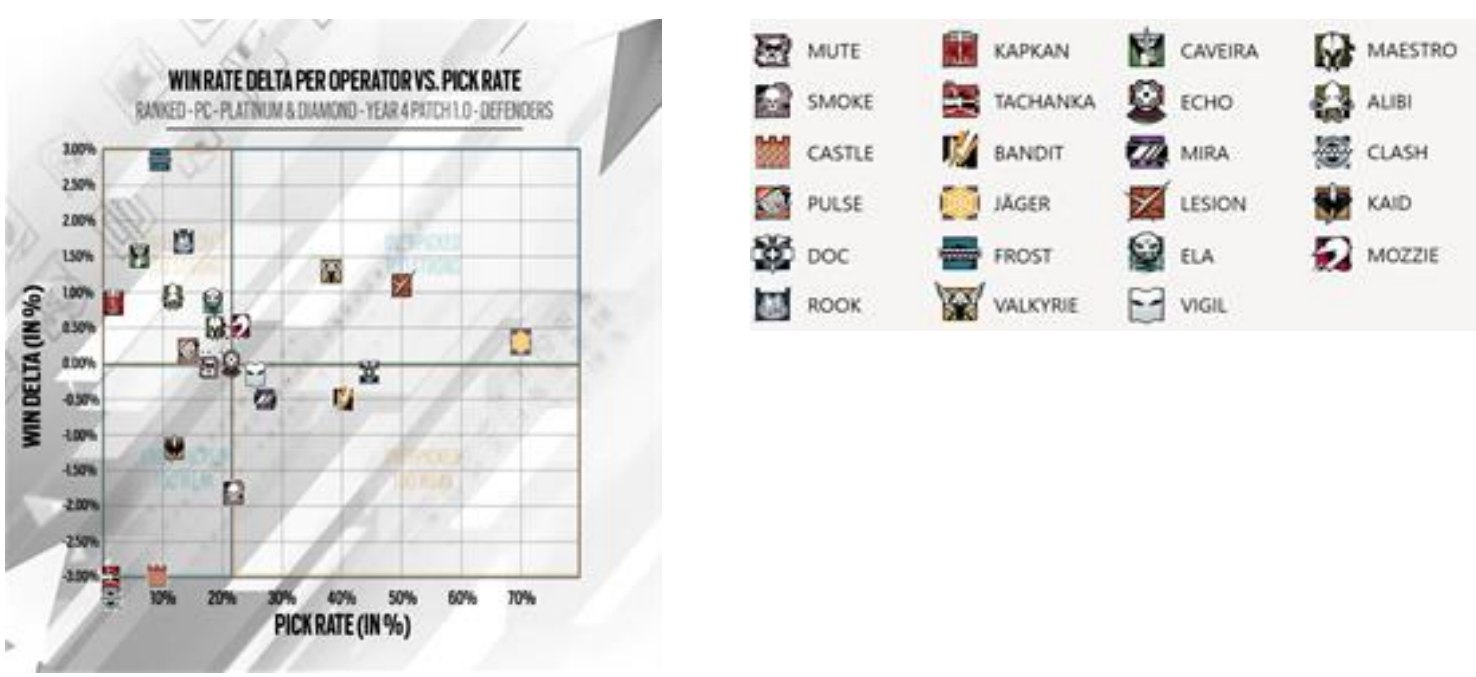

Figure 2. Stats for avatars of defending side

As one can see from above figures, operators are well balanced in pick rate and winning rate in that higher level players frequently choose operators of their trait in spite of relatively low winning rate which seems to be the highest goal of the game. Since this is a team game, team balance is crucial in winning and each operator has different ability and skills thus player's pick of the operators may exhibit the player's play habit or attachment to the avatar.

\subsection{Measurement of player-avatar relationship}

In player-avatar relationship studies, many different measuring schemes exist but those developed by Lewis et al. [10] are widely used with high reliability. That question are set consists of 4 factors of 17 questions and factors are identification/friendship, suspension of disbelief (intentional avoidance of critical thinking or logic in examining something surreal), control, and responsibility. In this research, unfortunately, when we took a pilot test in early 2019, we found that young Korean students had difficulty in differentiating several questions so that they tend to answer the same on several different questions of the same factor. Thus, we reduced the question are as 9 questions of 4 factors as the original one so that subjects would not be confused with the meaning and intention of the questions as shown in Table 1. We measure the relationship by using Likert 5-point scale from 1 (strongly disagree) to 5 (strongly agree). Factor 2 (suspension of disbelief) is negatively associated with the relationship thus we coded the score of factor-2 (Q4, Q5) reversely as instructed in [10]. 
Table 1. Measurement of player-avatar attachment

\begin{tabular}{ccl}
\hline Factor & Q number & \multicolumn{1}{c}{ Question } \\
\hline 1 & Q1 & I sometimes forget my own feelings and take on those of my character. \\
1 & Q2 & I enjoy pretending I am my character \\
1 & Q3 & I consider my character a friend of mine. \\
2 & Q4 & I direct my attention to possible errors or contradictions in the video game. * \\
2 & Q5 & I think about whether the action or the video game presentation was plausible. * \\
3 & Q6 & I enjoy controlling my character. \\
3 & Q7 & I get frustrated when my character does not perform the way I want him/her to. \\
4 & Q8 & I know what my character needs. \\
4 & Q9 & I make decisions with my character's best interests in mind. \\
Key & & *Reverse coded; \\
Factor 1 & & Identification/Friendship \\
Factor 2 & & Suspension of Disbelief \\
Factor 3 & & Control \\
Factor 4 & & Responsibility \\
\hline
\end{tabular}

\section{SURVEY RESULT AND ANALYSIS}

The online survey was conducted in June 2019 at the FPS mania Forum Bioshock Gallery (https://cafe.naver.com/fpsgame) where FPS manias are gathered. We ask only experienced Rainbow6 users should answer the question. With that limitation, only 55 subjects were willing to answer all questions and there was no female subject in this study. Players are grouped into three categories: attackers, defenders, and supporters. There were 18 attackers, 11 defenders, 23 supporters and 3 Mixed players who play many roles depending on the given environment. $70 \%$ were in their 20 's of age and $20 \%$ of teenagers but there was no significant age effect on our study goals.

Underlined scores in Table 2 show statistically significant differences by Scheffe's method. Overall, the attackers group shows the lowest and only significantly different scores thus we may safely say that attackers have lower character attachment rate. However, when we analyze three groups (Mixed group has only 3 subjects thus their statistics are not meaningful.) with respect to each factor, several interesting patterns are found.

Table 2. Player-avatar relationships with respect to group roles

\begin{tabular}{cccccc}
\hline Questions & Attack & Defense & Support & Mixed & Average \\
\hline Q1 & 1.69 & $\mathbf{2 . 9 0}$ & 1.87 & 2.50 & 2.04 \\
Q2 & 1.63 & $\mathbf{2 . 6 0}$ & 1.96 & 2.50 & 2.00 \\
Q3 & 1.69 & $\mathbf{2 . 8 0}$ & 2.00 & 2.00 & 2.06 \\
Factor 1 & 1.67 & $\mathbf{2 . 7 7}$ & 1.94 & 2.33 & 2.03 \\
Q4 & 2.50 & $\mathbf{2 . 0 0}$ & 2.78 & 2.50 & 2.47 \\
Q5 & $\mathbf{3 . 1 2}$ & 2.50 & 2.52 & 0.50 & 2.37 \\
Factor 2 & 2.81 & $\mathbf{2 . 2 5}$ & 2.65 & 1.50 & 2.42 \\
Q6 & 3.31 & 3.40 & 3.43 & 4.50 & 3.43 \\
Q7 & 2.50 & 2.30 & $\mathbf{2 . 7 8}$ & 4.50 & 2.67 \\
Factor 3 & 2.91 & 2.85 & 3.11 & 4.50 & 3.05 \\
Q8 & 3.13 & 3.00 & 3.09 & 5.00 & 3.16 \\
Q9 & 2.88 & 3.00 & $\mathbf{3 . 3 9}$ & 3.00 & 3.14 \\
Factor 4 & 3.01 & 3.00 & $\mathbf{3 . 2 4}$ & 4.00 & 3.15 \\
Average & $\mathbf{2 . 4 9}$ & 2.72 & 2.65 & 3.00 & 2.59 \\
Subjects & 18 & 11 & 23 & 3 & 55 \\
\hline
\end{tabular}

For factor 1 that represents identification/friendship, the defenders' group is significantly higher than others although their average score is just in the middle (neutral) for the absolute score. That means that FPS users have low character attachment in general, but defenders' group have some emotional connections to their chosen avatars.

For factor 2 that represents suspension of disbelief, the attacker's group show higher score than defenders' group since their failure cause the death or severe penalty of the game.

For factor 3 that represents control, all groups enjoy controlling their avatars (Q6) but in Q7, the supporters group have the most frustrated emotion since their failure frequently cause team's defeat.

For factor 4 that represents the responsibility, all groups understand avatar's need (Q8, no difference among groups) but the supporters group exhibit the highest responsibility in Q9. Combining Q7 and Q9, we can feel that the supporters' group is most sacrificing one for the team's winning. 


\section{CONCLUSION}

In this paper, we investigate the player-avatar relationship score as the measure of character attachment in team-based FPS game playing. Although this genre games have some story telling scheme, that is not the main goal of the game thus it was expected that the overall character attachment level would not be high. However, our focus was how this character attachment patterns are different with respect to the roles in the team-based FPS game.

We choose Tom Clancy's Rainbow 6 Siege as our theme game and took an online survey at the military game manias' cafe. The theme game has three different roles-attack, defence, support. By using simplified 9 questionnaire on 4 different factors of character attachment, subject shows different patterns. Attackers have the lowest character attachment level among three groups and extremely low identification score (Factor 1) but have the highest score on suspension of disbelief. That means this group plays the game with avatars as 'object'. Defenders show the highest identification (still not high in absolute value) and low in suspension of disbelief. There is no clear pattern for defenders but probably a mixture of 'avatar as object' and 'avatar as other'. Supporters group show highest responses in Q7 and Q9. This pattern of supporters' group is also not typical but probably similar to 'avatar as symbiote' except low identification score. Since this is probably one of the first few studies of exploring FPS players on the character attachment theme, the result encourages that a cross cultural studies are necessary in the future and hopefully we should prepare the reliable measurement for Korean players or East Asian players who seem to have different emotional pattern from western gamers.

\section{REFERENCES}

[1] Sigmund Freud, "The ego and the id," London: The Hogarth Press and the Institute of Psycho-Analysis, 1962.

[2] Hefner D., Klimmt C., Vorderer P., "Identification with the player character as determinant of video game enjoyment," International Conference on Entertainment Computing, vol. 4740, pp. 39-48, 2007.

[3] Zillmann D., "Basal morality in drama appreciation," In (Bondebjerg I, ed.) Moving images, culture, and the mind. Luton: University of Luton Press, pp. 53-63, 2005.

[4] Tamborini R., "Moral Intuition and Media Entertainment," Journal of Media Psychology Theories Methods and Applications, vol. 23, no. 1, pp. 39-45, 2011.

[5] Cohen J., "Defining identification: A theoretical look at the identification of audiences with media characters," Mass Communication and Society, vol. 4, no. 3, pp. 245-264, 2001.

[6] Lee H.J., "A Study on the Awareness of User's to Avatar Characters in the Cyberspace," Archives of Design Research, vol. 17, no. 3, pp. 61-70, 2004.

[7] Lee H.J., and Cho S.T., "A Study of community and avatar of virtual reality that appear in online game," Korea Design Forum, vol. 17, no. 26, pp. 21-32, 2010.

[8] Lee J.Y., and Yoon J.H., "Case study on application for avatar based on social role theory," SIGforum, vol. 1, pp. 174-191, 2011.

[9] Paik C.-H., "An analysis of correlations of users' attitudes toward avatars and identity play," Journal of Korea Game Society, vol. 17, no. 6, pp. 199-208, 2017.

[10] Lewis M.L., Weber R., Bowman N.D., "They may be pixels, but they're MY pixels: Developing a metric of character attachment in role-playing video game," CyberPsychology \& Behavior, vol. 11, no. 4, pp. 515-518, 2008.

[11] Bowman N., Schultheiss D., Schumann C., "I'm attached, and I'm a good guy/gal!,: How character attachment influences pro-and anti-social motivations to play massively multiplayer online role-playing games," Cyberpsychology, Behavior, and Social Networking, vol. 15, no. 3, pp. 169-174, 2012.

[12] Bowman N., Oliver M. B., Rogers R., Sherrick B., Woolley J., Chung M.Y., "In control or in their shoes? How character attachment differentially influences video game enjoyment and appreciation," Journal of Gaming \& Virtual Worlds, vol. 8, no. 1, pp. 83-99, 2016.

[13] Tamborini R., and Bowman N. D., "Presence in video games," In C. C. Bracken and P. D. Skalski, "Immersed in media: Telepresence in everyday life," Chapter 5, New York, NY: Routledge, pp. 87-112, 2010.

[14] Banks J., Bowman N.D., "Emotion, anthropomorphism, realism, control: Validation of a merged metric for playeravatar interaction (PAX)," Computers in Human Behavior, vol. 54, pp. 215-223, 2016.

[15] Banks J., Bowman N.D., Lin J.H.T., Pietschmann D., Wasserman J. A., "The common player-avatar interaction scale (cPAX): Expansion and cross-language validation," International Journal of Human-Computer Studies, vol. 129, pp. 64-73, 2019.

[16] Banks J., "Object, Me, Symbiote, Other: A social typology of player-avatar relationships," First Monday, vol. 20, no. 2, pp. 1-16, 2015.

[17] Banks J., Bowman N. D., "Avatars are (sometimes) people too: Linguistic indicators of parasocial and social ties in player-avatar relationships," New Media and Society, vol. 18, pp. 1257-1276, 2016.

[18] Ahn G. H., Yoo C. J., Kim S. H., "The Study on the Structural Model of Avartar Decoration Needs, Avatar SelfIdentification and Site Attitude \& Loyalty," Journal of Consumer Studies, vol. 15, no. 2, pp. 19-38, 2004.

[19] Park J. H., "A Study of the Effect of Avatar Identification on Loyalty and Purchase Intention of Avatar's item in Virtual Worlds: the case of Lineage I, II Users,” Ph. D. Dissertation, Yonsei University, Korea, 2009. 
[20] Wang H., Ruan Y. C., Hsu S., Sun C.T., "Effects of Game Design Features on Player-Avatar Relationships and Motivation for Buying Decorative Virtual Items," DiGRA '19-Proceedings of the 2019 DiGRA International Conference: Game, Play and the Emerging Ludo-Mix, 2019.

[21] Song W., Fox J., "Playing for love in a romantic video game: Avatar identification, parasocial relationships, and Chinese women's romantic beliefs," Mass Communication and Society, vol. 19, no. 2, pp. 197-215, 2016.

[22] Song D. H., Park S., Yang S. W., Yang Y., Won K., "Gender Differences and Gender Stereotype in Play Style among Young Korean Gamers," The Journal of the Korea Institute of Information and Communication Engineering, vol. 21, no. 1, pp. 72-81, 2017.

[23] Korea Creative Contents Agency, "White Paper on Korean Games 2019 (Annual Report)," Korea Creative Contents Agency, pp. 1-32, 2019.

[24] Rhee H. K., Song D. H., Kim J. H., "Comparative analysis of first person shooter games on game modes and weapons-military-themed, overwatch, and player unknowns' battleground," Indonesian Journal of Electrical Engineering and Computer Science (IJEECS), vol. 13, no. 1, pp. 116-122, 2019.

[25] Song D. H., Rhee H. K., Kim J. H.," Gender stereotype and hostile sexism among young korean gamers based on teammate selection strategy and game style preferences," Indonesian Journal of Electrical Engineering and Computer Science (IJEECS), vol. 19, no. 3, pp. 1512-1518, 2020.

[26] Song D. H., Rhee H. K., Kim J. E., Lee J. H., "From Agasa Cristie to Group Image Play-Analysis of Horror Survival Game Panic Room: Escaping from the Den on Emotional Elements Development," International Journal of Electrical \& Computer Engineering (IJECE), vol. 8, no. 2, pp. 644-650, 2018.

[27] Rainbow six siege, [Online] Avaible: https://www.ubisoft.com/en-gb/game/rainbow-six/siege/game-info/operators.

[28] Wong S., "How Ubisoft Keeps 'the Division' And 'Rainbow Six Siege' Ahead of The Competition," 2017. [Online]. Available: http://www.alistdaily.com/strategy/ubisoft-keeps-division-rainbowsix-siege-aheadcompetition/.

[29] "Rainbow six stats," 2019. [Online]. Available: https://r6.op.gg/?hl=en.

\section{BIOGRAPHIES OF AUTHORS}
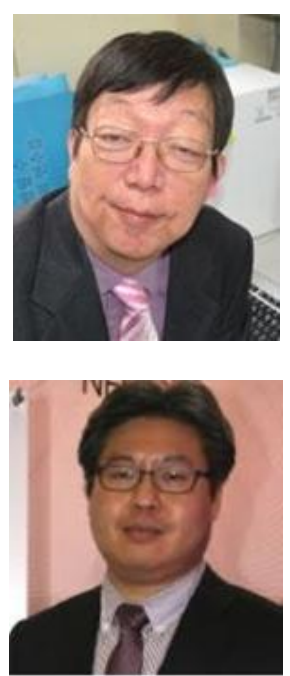

Doo Heon Song received his B.S. degree in Statistics \& Computer Science from Seoul National University, Korea and M.S. degree in Computer Science from the Korea Advanced Institute of Science and Technology in 1983. He received his Ph.D. Candidate Certificate in Computer Science from the University of California at Irvine in 1994. He has been a professor at the Department of Computer Games, SongDam College, Korea, since 1997. He has served as an associate editor for Journal of Multimedia Signal Processing and Information Hiding (SCOPUS/EI) and The Journal of Information and Communication Convergence Engineering (SCOPUS). His research topics include artificial intelligence, medical image processing, machine learning and video game design \& culture.

Seunghun Lee received his B.S., M.S., and Ph. D. in Computer Science from Soongsil University, Korea in 2002, 2005, 2012, respectively. He had been the president of Korea Game Developer's Association during 2006-2012. He has been a professor at the Department of Game Contents, Youngsan University, Korea since 2011 and he opens the first ever academic Department of Virtual Reality Contents in Korea since 2017 at the same university. Currently, he leads the VR contents committee in Korea Mobile Game Association and related with many game exhibitions such as G-star. His research interests include software engineering, software modelling of video game design, snd VR contents design. 